\title{
16. Challenges in Engaging Citizens as Partners in Housing
}

\author{
Shane Chisholm
}

I have a background in and a passion for frontline engagement with citizens, so my contribution to this volume is operationally focused. Since 2009, I have been the Customer Service Manager for the Housing New Zealand Corporation. In this role I am responsible for the development of a national strategy and associated program of work to enhance the customer service provided by the Housing New Zealand Corporation. The program is focused on increasing the levels of both internal and external customer satisfaction.

First though, what is the Housing New Zealand Corporation? As New Zealand has a long and proud history of serving its communities and meeting their housing needs, our mission statement is simple and clear: it is to help New Zealanders in their time of housing need. Our chief focuses are the identification of priority housing needs, the provision of appropriate housing solutions, and the provision of ongoing support to enable our customers a greater degree of independence. We also manage the Crown's social housing and resources, and we are obliged to do that efficiently.

We currently support over 200,000 customers through the provision of a number of housing-related products and services; our primary service is the 68,000 state-owned properties that are distributed throughout New Zealand. We have a wide and varied customer base.

The Customer First program, which is the focus of this essay, is one of a number of operationally focused programs that contributed to the Housing New Zealand Corporation's initial tranche of change. This transformative journey includes refreshing our information and communications technology (ICT) platform, introducing new finance systems and customer relationship management systems, and reconfiguring our service delivery model throughout New Zealand. The exciting thing about this is that, at the heart of the transformation, is a desire to become more customer-centric.

The Customer First strategy and initial work program was endorsed by Housing New Zealand's executive team in September 2009. The primary objective of the program was to initiate a process of change, to bring the customer to the forefront and, by doing so, identify opportunities to effect positive change in relation to the customer service experience. 
In saying that, however, there were three very simple goals established for this program. The first and most important goal was customer voice - to listen, to understand, and to respond appropriately to our customers. This goal was our initial focus, and it has influenced the activities and outcomes of the following two goals.

The second goal - customer focus - is about creating a service culture that encourages and enables our staff to deliver a customer service experience that meets and sometimes exceeds our customers' expectations. And the third goal is focused on customer choice, ensuring that Housing New Zealand has accessible, relevant, and user-friendly products and services.

In relation to the first goal, improving customer voice, there were three key areas on which it was necessary to focus. First, we had to review and align our existing quantitative and qualitative customer research, particularly customer satisfaction surveys. Second, we had to effectively manage complaints and compliments. Third, we had to better utilise the rich data that we had about our customers to better understand both the current and future customer profile.

Housing New Zealand had a number of existing customer satisfaction measurement activities and surveys, each operated in isolation of the other. We sought to consolidate these survey activities in order to ensure that we obtained an appropriate representation of all our customers. As a part of this consolidation activity we introduced the Kiwi's Count Common Measurement Tool. This is a concise and validated set of statements and questions that reflect our key customer satisfaction drivers. These measures are owned and used right across government in New Zealand, and across different government agencies.

We introduced transparent quarterly reporting across all channels. The results were published to all areas, for all areas. This promoted healthy discussion and sharing of best practice, enabling managers across the corporation to understand what was working well, what was not, and how they could collaborate to address problems.

The key to the customer satisfaction surveys and driving reform was that the satisfaction survey results became a core performance measure for the Corporation, automatically focusing our staff's attention on ensuring those results came through. The intelligence extracted from this research has informed future change; it has pointed us in the right direction by identifying the "pain points' for our customers, and has exposed things that the Corporation was reluctant to acknowledge.

The surveys provide us with good, clear direction. There are a number of other activities, such as focus groups, that the Corporation undertakes to identify 
the fundamental issues. But, that satisfaction levels have increased over time suggests that the information we are receiving, and the action we are taking, is having a positive impact on our customers.

The ability to share results and best practice - not only across the Corporation but also across agencies via the common measurement tool - has been a valuable experience. There have, however, been challenges, including acceptance of the common measurement tool as being relevant to assessing the type of customer encountered by Housing New Zealand. Our research and evaluation team reconfirmed, however, that there was a strong alignment between the previously completed research and these common measurement tools. Sharing our performance results was also, initially, a challenge for us as there was some reluctance to reveal progress.

We have also re-engineered how we manage and respond to complaints and compliments from our customers. Accessibility was a key to achieving this. Prior to this process of change, the only way a customer of the Corporation could register a complaint was in writing. To allow us to access this valuable information, it was essential that the complaints process was simplified. The benefit derived from this process was the opportunity that this feedback provided to learn from our mistakes, and to address the root cause of the issues. We are still working on that today.

The third area of focus is in relation to customer intelligence and, in particular, we focused on customer segmentation in order to understand the profile of both our current and future customers. This is a complex and long-term project.

As for our second goal — concerning our service culture - Housing New Zealand last year published its 'customer promise'. This represents a contract between Housing New Zealand and its customers that sets clear guidelines about the behavioural expectations of each party. It is based on our key customer satisfaction drivers, and therefore some level of our performance can now be measured from the customer satisfaction survey results.

Our customer promise is communicated proactively and regularly to our customers and this upfront investment in communication is fundamental. We spend time with our customers when they first engage with us through the customer promise process, and this has paid substantial dividends in the ongoing and long-term relationships that we have.

The promise comprises six statements about what the customer can expect from Housing New Zealand staff, and four statements in relation to how Housing New Zealand expects our customers to respond. This has been one of the most effective tools that we have used to change the culture - both internally and externally with the customer - of our customer service. 
We are also finding that our internal shared service partners are using the same promise to measure their own success with regard to engagement in the internal services they deliver to other areas within the organisation.

As well as the launch of the customer promise, there was a need to equip staff with understanding, knowledge, and tools to deliver on this promise. Consequently, the Service Excellence Training program was developed and delivered nationwide, providing staff with service standard guidelines on how to engage with our customers.

When we launched the customer promise, were we confident that we could deliver on it? The answer is no. But we were committed to improvement and progress, and that was the key.

To conclude, everything that Housing New Zealand learned from the Customer First program - a simple grassroots operational program — stems from listening to the customer. The volume of information that we have at our fingertips even without engaging our customer — was phenomenal, and the need for us to use that information to improve our service was evident. The valuable lessons learned include the need to 'keep it simple', to adapt process to meet needs and to undertake due diligence without impeding action. It is crucial to have strong, positive leadership in this area. Finally, internally, it is all about positioning to recognise and celebrate achievement, and encourage and support a teamwork environment. 